\title{
Forming Strategic Partnerships: New Results from the Revolutionizing Engi- neering and Computer Science Departments Participatory Action Research
}

\author{
Dr. Cara Margherio, University of Washington
}

Cara Margherio is Senior Research Associate at the UW Center for Evaluation \& Research for STEM Equity (CERSE). Cara serves as project manager for program evaluation on several NSF- and NIH-funded projects focused on diversity, equity, and inclusion within STEM higher education. Her research interests include community cultural wealth, counterspaces, faculty development, peer mentoring, and institutional change.

\section{Kerice Doten-Snitker, University of Washington}

Ms. Doten-Snitker is a Graduate Research Assistant at the University of Washington's Center for Evaluation and Research for STEM Equity, where she is part of a team conducting evaluation research for university-level educational and professional training, with a focus on increasing equity and participation of underrepresented and minority students and professionals. She has contributed to evaluation research for a range of programs funded by the NSF, NIH, and USAID. Additionally, she is a Doctoral Candidate in Sociology at the University of Washington, where her scholarship focuses on political processes of inclusion and exclusion.

\section{Dr. Julia M. Williams, Rose-Hulman Institute of Technology}

Dr. Julia M. Williams is Interim Dean of Cross-Cutting Programs and Emerging Opportunities and Professor of English at Rose-Hulman Institute of Technology. Her research areas include technical communication, assessment, accreditation, and the development of change management strategies for faculty and staff. Her articles have appeared in the Journal of Engineering Education, International Journal of Engineering Education, IEEE Transactions on Professional Communication, and Technical Communication Quarterly, among others.

\section{Dr. Elizabeth Litzler, University of Washington}

Elizabeth Litzler, Ph.D., is the Director of the University of Washington Center for Evaluation \& Research for STEM Equity (UW CERSE) and an affiliate assistant professor of sociology. She has been at UW working on STEM Equity issues for more than 12 years. Dr. Litzler is a member of ASEE and a former board member of the Women in Engineering ProActive Network (WEPAN). She is currently the principal investigator on a dozen different research and evaluation projects focused on improving equity, diversity, and inclusion in higher education. Her research interests include the educational climate for students in science and engineering, assets based approaches to STEM equity, and gender and race stratification in education and the workforce.

\section{Dr. Ella Lee Ingram, Rose-Hulman Institute of Technology}

Ella L. Ingram is an Associate Professor of Biology and Director of the Center for the Practice and Scholarship of Education at Rose-Hulman Institute of Technology. Her educational research interests include promoting successful change practice of STEM faculty, effective evolution and ecology instruction, and facilitating undergraduate research experiences. Her teaching portfolio includes courses on: nutrition, introductory biology, ecology and environmental studies, evolution, evolutionary medicine, and research practices in science. 


\title{
Forming Strategic Partnerships: New Results from the Revolutionizing Engineering and Computer Science Departments Participatory Action Research (REDPAR)
}

\begin{abstract}
This research paper investigates the formation of strategic partnerships, as experienced by teams of change agents in academic engineering and computer science. In this qualitative study of twelve teams making cultural, structural, and curricular change at their respective institutions, we examine the process of forming strategic partnerships through three initial stages: identifying potential partners, making an intentional approach, and establishing governance. We find teams have utilized a variety of strategies within each of these stages, such as establishing alignment of goals across the project team, the partner organization, and the home institution. These results delineate practices for initiating strategic partnerships within higher education and encourage faculty to build mutually beneficial strategic partnerships.
\end{abstract}

\section{Introduction}

There has been increasing interest in forming strategic partnerships in higher education due to a variety of motivations, such as pooling of resources, increasing accountability, and improving the professional development process for students [1]. This analysis of strategic partnerships emerges from our participatory action research with university change agents activated through the NSF REvolutionizing engineering and computer science Departments (RED) Program. Through an NSF-funded collaboration between Rose-Hulman Institute of Technology (RHIT) and the University of Washington (UW), we facilitate a consortium of the RED awardees (REDCON), providing support and training, while working with the change-making teams to investigate the process of change occurring at each of their institutions. Utilizing qualitative data from focus group discussions and observations of monthly cross-team teleconference calls, we examine the importance of motivations, goal-setting, social and organizational capital, and governance structures in the process of forming strategic partnerships.

Hoffman-Johnson [2] defines a strategic partnership within higher education as a "legal relationship among parties having specified, joint rights and responsibilities as they work together to achieve common goals within an integrated whole" (p.18). While the process of forming a partnership is iterative and not necessarily linear, prior researchers have identified the general steps that occur. Gray [3] outlines three phases of forming a strategic partnership: problem setting, direction setting, and implementation. Eddy [4] pushes this further, with the following eight steps: 1) verbalizing motivation and context for partnering, 2) aligning social capital of champions and leveraging organizational capital, 3) establishing partnership goals and team governance, 4) framing the partnership to stakeholders, 5) negotiating conflicts, 6) framing outcomes, 7) evaluating the process, and 8) institutionalizing the relationship. With this prior work in mind, this paper looks to the early stages of building strategic partnerships, as experienced by the RED grant awardees. It is important to examine how strategic partnerships form because the process of formation sets the objectives and expectations of the relationship, which in turn impact the likelihood of success and sustainability of the relationship. Further, despite the growing interest in forming strategic partnerships, the majority of these partnerships fail $[4,5,6]$. 


\section{Methodology}

This research is part of a project that is itself a partnership. In this case, the partnership is between a team of practitioners and social science researchers (REDPAR) and the REDCON teams. Because REDPAR viewed this research opportunity as a collaborative partnership with REDCON teams, we adopted a participatory action research approach. This approach recognizes the capabilities and valuable input of research subjects, undermining the traditional hierarchy between researcher and subject; it incorporates collaboration into research design and methodology [7]. As in a fruitful partnership, participatory action research works to create clear communication about goals and outcomes, and proceeds reflectively. Besides being a specific ethical approach to social science research, participatory action research is especially suited to the study context: the RED teams are comprised of individuals who are disciplinary experts in engineering and computer science fields, in social science, and in education research, all conducting their own research in their departments.

While the RED teams conduct research within their institutional environments, our work is focused on the process of change-making vis-a-vis the change-makers themselves. We are developing strategies and training for change-making based on challenges identified by us and by the participating REDCON teams. Because this is a partnership, we feed this information and training back to the teams while their projects are ongoing, to empower the teams to improve the implementation of their projects. We engage in a variety of activities that are often excluded in research studies: sharing of our research questions and methods with participant teams; soliciting both formal and informal input on lines of inquiry, findings, and research products; and collaborating to produce papers and presentations with participant teams and their individual members. We do not serve as evaluators on any of the projects; our interest is in description, inquiry, and synthesis across the teams' experiences.

\section{Context}

The RED funding mechanism is designed to support awardees in creating sustainable improvements in undergraduate persistence and in inclusive communities in engineering and computer science higher education. Awardees' curricular innovations focus on the middle years of undergraduate education; cultural and structural interventions target the whole local environment, including staff, faculty, and undergraduates at all stages. NSF envisioned that awardees would catalogue and study their change projects in order that the changes might be translated and adopted at other institutions. In service of this, NSF planned that awardees would work in a consortium that would provide internal support and external amplification of their projects.

The REDPAR team was tasked by NSF to facilitate the consortium and support its member teams by uniting the strengths of the RHIT members and the UW members. The RHIT members lead REDCON training on academic change through monthly REDCON calls, consultation, and annual in-person consortium professional development workshops. The UW members lead REDPAR research on the process of creating change, concentrating on describing and synthesizing across participant teams' change-making experiences. 


\section{Data Collection}

Since participatory action research is a conversation between partners, we collect qualitative data through focus groups and observations of monthly REDCON calls. Focus groups center the experiences and expertise of the participant teams and invite participants to dialogue with researchers. Participatory action researchers continue the conversation by reporting their findings with participants, sharing data, and asking for input and feedback on the findings.

In the first year of their RED grant, each team is invited to participate in a baseline focus group with UW researchers; in the third year of their RED grant, each time is invited to participate in a follow-up focus group. Focus group discussions are conducted via phone and/or video conference call. This paper utilizes data from the first three cohorts of RED teams' baseline focus group discussions $(n=18)$ along with the first cohorts' follow-up focus groups $(n=3)$. Baseline focus groups were designed to gather information on the initial stages of the change projects, and follow-up focus groups probed on implementation, adaptation, and the skills involved in academic change-making. Focus groups are especially helpful for this research as they allow team members to respond to and build on each other's comments [8]. Researchers become privy to individual and collective reasoning and motivations as the teams converse [9, 10] and recall how and why their experiences and actions intertwine to build the team's history and trajectory.

UW members of the REDPAR team also observed and transcribed each monthly REDCON call, while the RHIT members facilitated the calls. Oftentimes, the RHIT members split up and facilitated simultaneous calls for different configurations of REDCON members; at least one UW member was present on each call. For this paper, a total of 21 call transcriptions were coded and analyzed, representing all of the REDCON calls in the first two years of the RED grants.

\section{Data Analysis}

To develop change-making strategies, we rely on abduction, a reasoning approach that moves between deduction and induction. Abductive reasoning moves recursively between the data and theory building to remain open to new or contradictory findings, keeping existing theory in mind while not developing formal hypotheses [11]. Conducting research as a team of social scientists and practitioners creates regular opportunities to practice abduction. We discuss initial impressions before analysis, share research results, discuss potential interpretations, and dialogue about what initial impressions and theories still fit. In particular, the practitioners help the team maintain closeness to theories of change, and the social scientists help the team probe for where theory does not fit the data. Collaboration on interpretation introduces validity checks, as the team must work towards agreement on the best-fitting descriptions or explanations, and creativity to arrange and re-arrange ideas and interpretations through the writing process, resulting, hopefully, in more insightful and incisive conclusions.

We developed the coding scheme after reviewing six first-year focus group transcripts and first eight REDCON call transcripts and studies of academic change by Kezar $[12,13]$ and Kezar and Eckel [14]. During the coding process, we updated and revised the coding scheme with emergent codes and developed memos to explicate the coding categories [15] and the coding process. The full coding scheme included motivations, institutional cultural and organizational contexts, team 
dynamics, engagement with stakeholders and partners, communication strategies, and progress towards change goals. For this paper, we focus on the themes present within the 'engagement with stakeholders and partners' code. Please see Table 1 in the Appendix for the full coding scheme utilized in this paper. Each transcript was read three times and coded on the second and third reads using NVivo qualitative data software.

\section{Results}

In the early stages of strategic partnership formation, we find that the teams have been focused on: identifying potential partners, making an intentional approach to potential partners with whom they have shared interests, and establishing goals and governance for the operation of partnerships.

\section{Identifying Potential Partners}

RED teams have voiced a variety of reasons for building strategic partnerships as a part of their projects. These reasons include finding allies for their projects, attracting resources, supplementing skillsets, and navigating bureaucracy. In order to connect to potential partners, RED team members have leveraged their own social capital, building relationships through their pre-existing connections. For example, to partner with a faculty development program for improving campus diversity and inclusion, one team relied on "really good personal ties and investments from that group." Two teams' PIs were already involved in consortiums, one national and one state-level, whose missions complemented the teams' goals; their connections in these consortiums helped them find institutions and individuals who wanted to amplify and support the teams' work.

Some new partners were identified by looking at the local environment beyond teams' personal connections, in order to meet specific goals for their projects. Speaking about building a strategic partnership with their campus teaching center, one RED team member said, "My impression is that they are very eager to help, but most of their experiences are not in Engineering. I think they consider that as a challenge and an opportunity for them to learn from us." In a later conversation, this same team reflected back on the beginnings of this partnership and stated, "When we approached them and told them what we were planning, they got extremely excited." Thinking beyond conventional partners helped teams reach out to groups who were eager to collaborate but may have been overlooked or ignored in the past.

\section{Making an Intentional Approach}

Teams had opportunities, resources, and collaborative products they could offer to motivate partnership [16]. The value to partners might be through specific features of the change project, the organizational capital of the department or institution, or even factors entirely external to the project. Two teams experienced particular success through connecting to institutional initiatives that were unrelated to their projects. One of these teams was partnering with a campus-wide effort on communication skills; this team and the new partner attended each other's workshops. "We are trying to embed what we are doing into the bigger picture, so that the system will align with our hopes and aspirations," expressed a team member. When crossing disciplinary and 
organizational boundaries, partners' motivations were sometimes outside of what teams imagined the rewards to be. For example, one RED team noted:

we had a speed networking event with engineering and arts \& sciences to talk about the RED proposal and opportunities for collaboration between humanities and social sciences and engineering ... We [also] had someone from Art who is a sculptor; when she saw the size of our machine shop, "Maybe I have a real excuse to talk to you people."

Showing potential partners how the partnership aligned with their interests or commitments facilitated partnership formation.

\section{Establishing Goals and Governance}

RED teams have worked to establish supportive frameworks for their strategic partnerships by aligning goals and activities, building on their partner's strengths, and creating mutually beneficial relationships. One team discovered that highly-involved staff members were champions of their projects because they "see these types of projects as more aligned with their job."

In the most effective partnerships, RED teams invite partners into a visioning process that reflects the ideas of the partners, not just that of the original team. Teams empowered their partners through formational communication, inviting stakeholders to contribute to the change process through offering alternative or additional ideas for goals or how to implement the change [16]. For example, one team described this process as follows:

We invited our advisory board to participate in brainstorming process with uswhat are their perceptions for needs for change. And that was immensely beneficial. We repeated that in year two refining our ideas based on their comments.

Two other teams reported similar processes with their industrial advisory boards. A member of one of these teams remarked that a great benefit of their relationship with their board was "the advisory board seeing how they could contribute to the project now and over time." The other team developed a new project component through the leadership of the board, meeting needs in professional training that the board identified and using the board's capacities to develop and implement the new component.

Two teams brought up potential partnerships where they had mutual interest but had not yet decided with their partners what they should focus on. "We haven't quite figured it out, but they very much want to partner with us, so we want to explore this a bit more," explained one team member. A member of another team related, "I just got an email today, and they are excited about moving forward on this...We are brainstorming."

\section{Discussion}

As demands for change in STEM education in the United States grow, projects like NSF RED provide useful models for transforming how engineering and computer science are taught. What 
we are learning from the REDPAR project is that educational transformation requires more than an innovative idea in order to succeed. In fact, the scope and scale of systemic change points to the essential need for partnerships across disciplines and departments. As Gray [3] argues, independence is no longer a suitable approach to problem-solving and interdependencies are necessary for institutional success. Further, strategic partnerships increase efficiency and efficacy within higher education [2].

As the research on change associated with the RED projects suggests, strategic partnerships are one way to ensure that educational innovations create systemic impact and are sustainable longterm. These results delineate practices for initiating strategic partnerships within higher education and encourage faculty to build mutually beneficial strategic partnerships. Our findings highlight the need engage in an expansive search for potential partners and to leverage social capital to form these relationships. Further, it is vitally important to create partnerships that are mutually beneficial, so that all individuals and groups involved are equally committed. The REDPAR work has indicated that RED teams must consider their projects and its products from the perspective of the partner in order to appreciate how the partner benefits from the collaboration. This perspective includes what the partners' interests and needs are and what they stand to gain from the collaboration.

Even as our work suggests that strategic partnerships are key to RED projects, the research literature about strategic partnerships suggests that the majority of these relationships fail $[4,5$, 6]. Failure is often attributed to the lack of goals and governance that provide an operational framework for groups that have not worked together previously. Key to this work is the recognition that all partners need to engage in developing a shared vision for the project. As Worrall [1] has noted, "Good partnerships are founded on trust, respect, mutual benefit, good communities, and governance structures that allow democratic decision-making, process improvement, and resource sharing" (p.5). Through shared vision building and democratic decision-making, these strategic partnerships may provide a framework to sustain changes for the long-term. 


\section{Appendix}

Table 1. Qualitative Coding Scheme

\begin{tabular}{|c|c|}
\hline Code & Meaning \\
\hline Stakeholders & $\begin{array}{l}\text { any stakeholder group mentioned, from direct participants to end- } \\
\text { users to indirect beneficiaries, etc }\end{array}$ \\
\hline administration & $\begin{array}{l}\text { institution administration/leadership, e.g., deans, provosts, } \\
\text { presidents }\end{array}$ \\
\hline alumni & alumni \\
\hline faculty & $\begin{array}{l}\text { faculty, including research faculty; implied instructional } \\
\text { responsibilities }\end{array}$ \\
\hline $\begin{array}{l}\text { graduate students } \\
\text { non tenure track }\end{array}$ & graduate students \\
\hline $\begin{array}{l}\text { faculty } \\
\text { outside perspectives }\end{array}$ & $\begin{array}{l}\text { non-tenure-track faculty, e.g., lecturers, adjuncts, clinical faculty } \\
\text { advisory boards, practitioner/professional groups, centers or } \\
\text { institutes no explicitly involved in the grant, specific companies, } \\
\text { other funding organizations }\end{array}$ \\
\hline staff & $\begin{array}{l}\text { administrative and instructional support staff; university staff in } \\
\text { the focal unit or explicitly engaged in the change process }\end{array}$ \\
\hline students & $\begin{array}{l}\text { undergraduate students; mentions of "students" without specifying } \\
\text { grad vs undergrad are assumed to be undergrad }\end{array}$ \\
\hline Collaboration & working with others to accomplish RED goals \\
\hline campus partners & $\begin{array}{l}\text { partnerships or collaboration with campus centers/institutes, } \\
\text { departments, schools }\end{array}$ \\
\hline admissions & $\begin{array}{l}\text { specifically, collaboration with an admissions department, at the } \\
\text { institution or college level }\end{array}$ \\
\hline cross-disciplinary & $\begin{array}{l}\text { collaboration with a partner explicitly in another discipline, e.g., } \\
\text { another unit or college }\end{array}$ \\
\hline resistance & $\begin{array}{l}\text { presence, absence, or anticipated resistance to collaboration or } \\
\text { cooperation }\end{array}$ \\
\hline reward & payoffs, incentives, rewards for collaboration or cooperation \\
\hline Internal support & $\begin{array}{l}\text { support for designing and implementing a change process from } \\
\text { inside the institution }\end{array}$ \\
\hline mentorship & $\begin{array}{l}\text { formal or informal mentorship of change agents or change leaders } \\
\text { as an explicit part of the change process }\end{array}$ \\
\hline $\begin{array}{l}\text { staff and faculty } \\
\text { development }\end{array}$ & $\begin{array}{l}\text { staff and faculty professional development opportunities as an } \\
\text { explicit part of the change process }\end{array}$ \\
\hline External support & $\begin{array}{l}\text { support for designing and implementing a change process from } \\
\text { outside the institution }\end{array}$ \\
\hline RED cohort & $\begin{array}{l}\text { reflections (impacts, value, needs) of connection to other RED } \\
\text { teams, at annual meeting, on calls; RED teams providing training } \\
\text { to other teams }\end{array}$ \\
\hline
\end{tabular}




\section{References}

1. Worrall, L. (2007). Asking the Community: A Case Study of Community Partner Perspectives. Michigan Journal of Community Service Learning, 14(1), 5-17.

2. Hoffman-Johnson, G. (2007). Seamless transition in the twenty-first century: Partnering to survive and thrive. New Directions for Community Colleges, 2007: 17-27.

3. Gray, B. (1989). Collaborating: Finding common ground for multiparty problems. San Francisco, CA: Jossey-Bass Publishers.

4. Eddy, P. L. (2010). Partnerships and collaboration in higher education: AEHE. John Wiley \& Sons.

5. Farrell, P. L., \& Seifert, K. A. (2007). Lessons learned from a dual-enrollment partnership. New Directions for Community Colleges, 2007(139), 69-77.

6. Reed, G. G., Cooper, J. E., \& Young, L. (2007). A partnership in flux: The demise of a program. New Directions for Community Colleges, 2007(139), 79-90.

7. Case, J. M., \& Light, G. (2011). Emerging Methodologies in Engineering Education Research. Journal of Engineering Education, 100(1), 186-210.

8. Lofland, J., \& Lofland, L. H. (2006). Analyzing social settings. Belmont, CA: Wadsworth Publishing Company.

9. Ansay, S. J., Perkins, D. F., \& Nelson, C. J. (2004). Interpreting outcomes: Using focus groups in evaluation research. Family Relations, 53(3), 310-316.

10. Morgan, D. L. (1996). Focus groups. Annual Review of Sociology, 22(1), 129-152.

11. Timmermans, S., \& Tavory, I. (2012). Theory construction in qualitative research: From grounded theory to abductive analysis. Sociological Theory, 30(3), 167-186.

12. Kezar, A. (2001). Understanding and facilitating organizational change in the 21 st century. ASHE-ERIC Higher Education Report, 28(4), 147.

13. Kezar, A. (2014). How colleges change: Understanding, leading, and enacting change. New York: Routledge.

14. Kezar, A., \& Eckel, P. (2002). Examining the institutional transformation process: The importance of sensemaking, interrelated strategies, and balance. Research in Higher Education, 43(2), 295-328.

15. Charmaz, K. (2001). Grounded theory. In R.M. Emerson (Ed.) Contemporary field research: Perspectives and formulations (pp. 335-352). Long Grove, IL: Waveland Press, Inc. (Original work published 1994)

16. Doten-Snitker, K., Margherio, C., Litzler, E., Ingram, E., \& Williams, J. (2018). Developing a Shared Vison for Change: Moving toward Inclusive Empowerment. 